\title{
NÉ/NÃO É? - UMA ABORDAGEM DISCURSIVA
}

\author{
Elsa Maria Nitsche Ortiz
}

RESUMO: Bien que la formule abrégée né soit une structure syntaxique très employée en Portugais, principalement dans les régions du sud du Brésil, elle est presque toujours oubliée dans les descriptions linguistiques traditionnelles. De ce fait, nous nous sommes proposés à l'étudier sous l'optique de l'Analyse de Discours $(A D)$ ligne française: chercher les positions occupées par le sujet et par l'autre $(O)$, leurs formations imaginaires et, par conséquent, les effets de sens obtenus par l'emploi de cette forme linguistique. On a ainsi pu observer que né doit être pris comme un élément méta-linguistique qui peut indiquer des points d'hétérogéneité discursive.

PALAVRAS-CHAVE: Discurso, heterogeneidade, metalinguagem.

\section{À GUISA DE INTRODUÇÃO}

O objetivo deste estudo é o exame da hipótese que vê vários efeitos de sentido veiculados pela partícula né - produto lingüístico insistentemente presente em cenas enunciativas instanciadoras de práticas discursivas, em que estão explícitos os elementos constitutivos da relação dialógica, isto é, indivíduos que podem ocupar a forma-sujeito vazia e virtual de uma Formação Discursiva (FD). Para tal, usaremos constructos teóricos formalizados pela Análise de Discurso de linha francesa $(\mathrm{AD})$, como a concepção de uma heterogeneidade da realidade social no processo discursivo bem como a heterogeneidade constitutiva do sujeito e, conseqüentemente, de seu discurso. No caso específico de situações dialógicas, o sujeito e o outro se interpenetram reciprocamente, interpelados por suas formações imaginárias.

As seqüências discursivas que nos servem de referência provêm de um corpus de arquivo formado por entrevistas com elementos do corpo administrativo, docente e discente de quatro escolas públicas e particulares de Porto Alegre. Os dados registrados entre parênteses após a seqüência discursiva de referência 
remetem à fita cassete em que a referida entrevista foi gravada, e o sinal [+] marca uma pausa. ${ }^{1}$

\section{PRIMEIROS EMPECILHOS E PRIMEIRAS PISTAS}

Geralmente, as várias teorias lingüísticas que trabalham sob os mais diferentes enfoques concordam quanto à necessidade de ser levada em conta a existência de uma tradição gramatical zelosa da nomenclatura usada em seus estudos morfológicos, sintáticos e semânticos, essencialmente direcionados às normas que orientam, ou que deveriam orientar, segundo tal ótica, a linguagem. Entretanto, como gramáticas fundamentalmente normativas que são, esquecem-se da fala. E a partícula né pertence ao registro falado da língua. Em outras palavras: quase nada foi encontrado nas chamadas gramáticas normativas tradicionais.

A primeira pista surgiu no verbete $\hat{E}$ tre do dicionário Le Petit Robert (1972), apresentando o uso da estrutura N'est-ce pas?, equivalente francês do enunciado português Não é?, como uma fórmula que solicita a adesão do interlocutor.

Rememorações lingüísticas levaram-nos a formulações como Nicht wahr?, imediatamente confirmada pelo Dictionnaire Allemand-Français/FrançaisAllemand, da Garnier-Flammarion (1964) e a isn't? inglês; esta, sim, confirmada por uma linha normativa, que, todavia, referencia usos conversacionais (ECKERSLEY, 1960, p.183).

Assim sendo, tomaremos como ponto de partida a consideração da partícula né como uma estrutura sintática, reduzida de não é?, posposta a uma outra asserção e que tem o efeito de sentido mais comum, à semelhança de outras línguas modernas, a solicitação de concordância do interlocutor à asserção anteriormente enunciada pelo locutor.

\section{O ENFOQUE DISCURSIVO}

De imediato constatam-se duas características da forma né: (a) é facilmente eliminada da cadeia discursiva em que se insere; (b) refere-se sempre a um segmento desta mesma cadeia. Tais particularidades dão-lhe o estatuto de forma metaenunciativa capaz de produzir um efeito de sentido próprio, simultâneo ao dizer principal do ato enunciativo, denunciando a presença, ou pelo menos o temor da presença, de uma não-coincidência do dito entre o sujeito e o outro interlocutivo.

A noção de não-coincidência interlocutiva foi introduzida por AuthierRevuz (1990) e definida como alterações locais do dizer (op. cit., p.174), isto é,

\footnotetext{
${ }^{1}$ Tal arquivo pertence ao Grupo de Pesquisa em AD do Curso de Pós-Graduação em Letras da PUCRS, ao qual agradeço as sugestões e pareceres discutidos.
} 
pontos que denunciam rupturas discursivas. Para a autora, essas alterações podem ser reunidas em quatro grupos: (a) pontos de não-coincidência dentro do próprio discurso, situação que ocorre quando aparecem ditos pertencentes a outros discursos, evidenciando, assim, fronteiras permeáveis entre os discursos; (b) pontos de não-coincidência entre as palavras e seus objetos, quando o sujeito procura a palavra considerada mais exata; (c) pontos de não-coincidência entre as próprias palavras, cabendo ao sujeito delimitar o significado da palavra usada, restringindolhe a polissemia; (d) pontos de não-coincidência interlocutiva, demonstrando que os interlocutores não compartilham total ou parcialmente do dito. Em sua análise, Authier-Revuz valeu-se das glosas lingüísticas para comprovar a presença dessas alterações.

É nossa hipótese que, através da forma né, instaura-se uma negociação entre os ocupantes de lugares discursivos sejam eles de uma mesma formação discursiva (FD) ou de formações discursivas diferentes para que uma presumível não-coincidência seja eliminada ou, pelo menos, atenuada.

Nas sequiências discursivas que nos servem de referência verificam-se algumas variações quanto aos tipos de não-coincidência interlocutiva que, cremos, instauram-se, através da forma né, uma negociação entre os interlocutores.

\section{Não-coincidência quanto ao conhecimento da informação veiculada pela asserção em que se insere o né}

(1) a nossa atuação a nível de SOP está um pouquinho diferente, uma vez que nós estamos retomando no SOP, né [+], as três (professoras são) novas no SOP, né, então a gente tá pegando a caminhada junto com a nova direção (fita 11, lado A).

Embora os interlocutores pertençam à mesma $\mathrm{FD}$, tenham conhecimento disto e por isto mesmo suas representações imaginárias sejam semelhantes, o sujeito pressupõe o desconhecimento do outro quanto às mudanças ocorridas no sistema pedagógico da escola e enfatiza a nova informação. A forma metaenunciativa se refere a toda nova informação.

Efeito de sentido semelhante encontramos em (2) e (3):

(2) são três períodos de português [...] e um de redação, que é de outro professor, no caso eu, né (fita 1, lado A).

(3) [...] deram um curso só para professores de português, e os nossos participaram todos, $n e ́$ (fita 28 , lado A).

com a diferença mínima de que em (2) e (3) né se refere a um segmento menor da informação.

Os novos elementos informativos devem ser, de acordo com o sujeito, aceitos e incorporados pelo outro. 


\section{Temor de não-coincidência de um elemento do saber entre os interlocutores pertencentes a uma mesma FD}

(4) anualmente a gente revisa (os conteúdos programáticos) [...] e aí novamente a gente altera, altera alguma coisa né [+] de acordo com a realidade que a gente vai vivenciando (fita 19, lado A, $3^{\text {a }}$ entrevista).

O sujeito sabe que o outro, por ser também um professor, deverá pertencer a uma FD semelhante a sua, compartilhando, assim, diversos elementos do saber de tal FD. As formações imaginárias que o sujeito faz de si e do outro contribuem para que a idéia de tal compartilhar seja desejada.

Em (4), o elemento do saber é a adequação dos programas à realidade, materializado intradiscursivamente pela formulação discursiva alterar alguma coisa. O uso do né visa mostrar esse compartilhar profissional e ao mesmo tempo impedir uma recusa potencial pelo outro. $\mathrm{O}$ sujeito quer fazer crer na existência de uma homogeneidade entre os saberes. em (1).

Vejamos o exemplo (5), que faz parte da seqüência discursiva apresentada

(5) [...] então a gente tá pegando a caminhada [...] junto com a nova direção [...] está colocando um ensino mais atual, mais crítico, né (fita 11, lado A).

O sujeito expressa sua crença na concordância do outro quanto à coincidência de mensagem do dito, ambos professores, imaginariamente mais atualizados, desejando um ensino mais crítico. A forma né tem o efeito de mostrar que há uma concordância.

Se, entretanto, né tivesse sido colocado depois da palavra atual, teria como efeito de sentido a veiculação de uma nova informação: a atualização pedagógica proposta pela nova direção, conhecimento hipoteticamente não compartilhado pelo outro.

\section{Não-coincidência no próprio discurso}

(6) (A) como tu te sentes ao utilizar o livro?

(B) olha, depois de ter feito essa escolha, né, que foi [+] nós não tivemos assim muita escolha, né [...] (fita 1, lado A).

A existência de uma heterogeneidade discursiva é sublinhada pela dupla estratégia de ênfase: repetição do item lexical escolha e da partícula né. Poder-se-ia levantar a hipótese de que, pela escolha de tais estratégias, se instaura um diálogo entre as vozes constitutivas do próprio sujeito, configurando-se, assim, uma nãocoincidência dentro do próprio discurso: a FD da escola a que pertence lhe faz dizer que os professores podem escolher o livro didático, o que é sublinhado pela primeira ocorrência de né, mas, ao mesmo tempo, lhe tolhe a possibilidade de uma crítica explícita, sobre essa escolha quando ocorre o segundo caso de né, alterando significativamente o dito.

Situação semelhante pode ser verificada em (7): 
(7) (A) quem elabora os conteúdos programáticos [...]?

(B) é [+] a equipe de professores, juntamente com o SOP, no caso o segundo grau, é toda a equipe né, de $1^{\text {a à }} 3^{\text {a }}$ série (fita 1 , lado A).

A forma né, ao interromper o sintagma, tem o efeito primeiro de enfatizar o segmento toda equipe, já anteriormente apresentado como informação nova. Entretanto, esse primeiro efeito de sentido de né poderia ser tomado como indicativo de um jogo de poder entre SOP e professores, evidenciando uma ruptura discursiva.

\section{Não-coincidência no próprio discurso: recusa de um elemento do saber da FD}

(8) (A) tu gostas de ler [+] por quê?

(B) porque já é uma maneira de ficar um pouco mais desligada, né [+] tu lê, tu entende mais as coisas e também não precisa ficar pensando muito, né (fita 20, lado A, $2^{\mathrm{a}}$ entrevista).

O sujeito, aluna de $7^{a}$ série do $1^{\circ}$ grau, demonstra, através da primeira ocorrência de né, sua negação a um elemento do saber da própria FD a que está assujeitada: a instituição escolar preconiza a leitura como um instrumento de inserção do aluno nas formações discursivas ideológicas e culturais, como forma de fazê-lo pensar mais, de refletir sobre os mais diversos aspectos do mundo que o rodeia. Há uma clara ambigüidade, enfatizada pela segunda ocorrência de né, entre entender mais e não precisar ficar pensando muito, característica do processo de denegação pelo qual o sujeito em questão está passando. A este efeito de sentido, acrescenta-se um outro: sujeito solicita a outro, se não a adesão, pelo menos sua compreensão.

\section{Né nos diálogos com crianças}

No corpus coletado, houve uma constatação muito importante quanto ao uso de né com crianças de $3^{\mathrm{a}}$ série do $1^{\circ}$ grau, cuja faixa etária vai dos oito aos dez anos. Em um universo de nove entrevistas houve apenas quatro ocorrências, com dois sujeitos diferentes. Dada a raridade do fato, é conveniente, pois, observá-las.

(9) (A) [...] das aulas de linguagem, de Língua Portuguesa, gosta por quê?

(B) Hum, sei lá, né (fita 18, lado A, $1^{\text {a }}$ entrevista).

(10) (A) e esses livros que ela traz [...] são dela ou são da escola?

(B) da escola.

(A) da escola; da biblioteca ou tem em sala de aula, material?

(B) ai, é que eu não sei, porque eu nunca fui lá, né (fita 18, lado A).

(11) (A) por que tu gostas (das aulas de linguagem)?

(B) ai, porque eu acho interessante aprender assim a falar direito né [+] porque eu acho interessante (fita 4 , lado B).

(12) (A) por que é que tu gostas (de trabalhar com polígrafos)?

(B) ah, porque eu acho, eu acho legal né. 
Piaget (1989) distingue dois modelos de linguagem infantil por volta dos 6-8 anos: o egocêntrico ${ }^{2}$ e o socializado. Se no primeiro tipo a criança não procura colocar-se no ponto de vista do interlocutor, nem agir sobre o mesmo, bastando-lhe ser escutada, é no segundo tipo - o dizer socializado - que permite haver realmente uma troca entre os interlocutores, pois a criança tanto presta informações como faz críticas, sempre adaptadas a um determinado interlocutor e responde também a perguntas explícitas.

Embora na linguagem egocêntrica já possam surgir processos socializadores, a estratégia de maior ocorrência nesta fase é o monólogo coletivo, em que a criança parece falar consigo mesma. É por ocasião da introdução à linguagem socializada, por volta dos oito anos, que a criança tem acesso ao diálogo, definido por Piaget como sendo a ocasião em que "o interlocutor responde a uma proposição, falando do objeto de que se trata nessa proposição" (op. cit., p.15). Conseqüientemente, é nesta mesma etapa de vida que a criança tem ingresso ao "estádio de colaboração e de discussões verdadeiras" (op. cit., p.87), em que se generalizam os fenômenos lógicos de reflexão, isto é, de unificação e sistematização de opiniões.

Em (9), percebe-se nitidamente que o sujeito -9 anos, escola pública de periferia - não está dialogando com o interlocutor: seu diálogo, marcado por né, ainda é interior, é como se ele refletisse em voz alta; como se solicitasse ao interlocutor uma pausa para poder pensar e responder com maior precisão.

Em (10), o mesmo sujeito demonstra estar ingressando no estádio socializado da linguagem, isto é, já dialoga com interlocutor, embora a presença de né possa querer mostrar também que o diálogo se situa no nível de uma heterogeneidade constitutiva do sujeito.

Em (11) o sujeito - 9 anos, tradicional escola particular — já demonstra sua tomada de consciência da existência de opiniões que podem ser contrárias à sua, o que é materializado na estrutura eu acho. A fala socializada piagetiana é indicativa da presença do discurso do outro, da introdução do sujeito em uma formação discursiva. A ocorrência de né de (11) enfatiza a aceitação por parte do sujeito do saber da FD da Escola: "a escola ensina a falar bem". A estrutura né parece-nos indicar que o sujeito quer mostrar ao interlocutor que ambos compartilham o mesmo elemento do saber, isto é, que o sujeito, embora só tenha 9 anos, já sabe que o outro, por ser professor, também é partidário da idéia de que a "Escola ensina a falar bem". Né demonstra claramente que o sujeito já se acha inserido em uma fala socializada pertencente a uma formação ideológica definida.

Em (12), o mesmo sujeito interioriza-se, dialogando com outras vozes formadoras de sua subjetividade.

\footnotetext{
${ }^{2}$ Lacan (1985), entretanto, discorda de Piaget quanto à existência da fase egocêntrica da linguagem infantil. Apoiado em estudos freudianos, Lacan afirma ser o homem, desde sua mais tenra idade, interpelado como sujeito pela linguagem do outro.
}

160 


\section{Né/Não é?}

No corpus analisado muito raras são as ocorrências da forma completa não é?. Tal uso parece-nos estar intimamente relacionado às formações imaginárias que o sujeito tem de si próprio e do outro. As formulações discursivas que nos proporcionaram tais constatações pertencem a sujeitos que, ou ocupam posição hierárquica de destaque na instituição de ensino a que pertencem, ou a quem foi comunicado que os entrevistadores eram professores universitários, doutores ou doutorandos em Lingüística Aplicada.

Os efeitos de sentido da estrutura não é? podem ser considerados semelhantes aos obtidos por né, com uma pequena diferença: não é? parece manter o significado implícito original "não é verdade que você adere à asserção que acabei de enunciar?", o que é comprovado até mesmo pela pausa que geralmente se segue, como que à espera de uma resposta. ${ }^{3}$

(13) (A) e como tem sido o desempenho dos alunos?

(B) nas $5^{\mathrm{a}}$ e $6^{\mathrm{a}}$ séries eles gostam de se expressar, não é [++]. (No $2^{\circ}$ grau) as professoras constantemente se queixam de grande dificuldade do aluno querer expressar o que lê, ou mesmo ler, não é (fita 28, lado A). (14) (A) qual é prá ti a função do ensino de Língua Portuguesa?

(B) [...] para que o aluno possa se expressar melhor, não é [++] e utilizar a língua como meio de comunicação, não é? (fita 2, lado B).

Através do emprego de não é? o sujeito quer enfatizar a coincidência discursiva entre ele e seu interlocutor. Parece procurar uma perfeita sintonia discursiva capaz de referendar o que foi dito.

\section{CONSIDERAÇÕES FINAIS}

As seqüências discursivas que nos servem de exemplo possibilitaram-nos comprovar o seguinte:

a) à semelhança do emprego da estrutura completa, no uso da forma reduzida né, a exigência constitutiva de uma situação dialógica se mantém, modificando-se, entretanto, o estatuto do interlocutor: o sujeito pode dialogar com um outro indivíduo que ocupa a forma-sujeito virtual de outro (o outro lacaniano) bem como pode dialogar com uma outra voz, formadora de sua própria heterogeneidade subjetiva.

É sob esse enfoque que toda e qualquer manifestação lingüística pode ser analisada como portadora de sentido - até mesmo o uso de né como uma forma estereotipada, como cacoete - ou seja, como pedido de uma pausa, de um tempo, como reparo ou reflexão sobre o que foi dito;

b) o sentido original, de solicitação de adesão do interlocutor discursivo foi mantido em alguns casos. Houve, contudo, uma fragmentação deste significado

\footnotetext{
3 A audição das entrevistas permite-nos afirmar que o uso da forma reduzida né não é marcada sonoramente por uma entonação montante, fato que ocorre quando do uso de estrutura não reduzida.
} 
inicial de solidariedade co-enunciativa, que propiciou a criação de novos efeitos de sentido, praticamente desvinculados da estrutura que os gerou;

c) o inexpressivo número de ocorrência de né nas entrevistas com crianças pode ser o resultado de uma não-simetria entre os interlocutores - idades diferentes e, conseqüentemente, saberes não-compartilhados. Se em nosso corpus houvesse ocorrência de diálogos entre crianças da mesma faixa etária, que compartilham de interesses idênticos, poderíamos, talvez, chegar a uma outra conclusão;

d) uma análise da entonação - elemento supra-segmental da linguagem - poderia comprovar que né perde grande parte de seu efeito de sentido original, já que raramente os sujeitos entrevistados usam a entonação montante, características das formas interrogativas, o que não ocorre quando é usada a forma não-reduzida não é?.

A dimensão discursiva de nossa abordagem permite o deslocamento da forma né do plano sintático — onde ela é vista como mera partícula expletiva, vazia de sentido - para o plano semântico, como elemento portador de processos de significação.

\section{BIBLIOGRAFIA}

AUTHIER-REVUZ, J. La non-coïncidence interlocutive et ses reflets métaénonciatifs. In: BERRENDONNER, Alain. (org). L'interaction communicative. Berne-Paris, Peter Lang, 1990.

ECKERSLEY, C. E. A Comprehensive English Grammar. Londres, Longmann, 1960.

LACAN, J. Seminário - livro XI. Rio de Janeiro, Zahar, 1985.

PIAGET, J. A linguagem e o pensamento da criança. São Paulo, Martins Fontes, 1986.

ROBERT, Paul. Dictionnaire alphabétique et analogique de la langue française. Paris, S.N.L. Dictionnaire Le Robert, 1972.

VLLLAIN, P. S. (org). Dictionnaire allemand-français/français-allemand. Paris, Garnier Flammarion, 1964. 
Perspectiva da Semiótica 
